\title{
Personal Growth, Creativity and Transcendence in Old Age. A Psychological Analysis
}

\section{Life issues in old age}

This chapter should begin with some basic questions that people ask themselves at biographical turning points, and thus also in old age: Who am I, where do I come from, where do I go? We owe the following verse to the German Renaissance poem, which expresses these questions very well - a piece of anonymous verse: "I come and I don't know from where. I am and I don't know who. I go and I don't know where. And I'm surprised that I am so happy."1

What moves people in old age? What joys, worries and burdens does their current life have? How do they assess their current life situation and how do they see the future? What hopes and fears do they mention when looking to the future? We dealt with these questions in a recently completed research project in which we extensively interviewed $\underline{\mathrm{N}}=400$ people in the 75 to 95 age group (Kruse etal. [in press]; Kruse and Schmitt [in press]). The present article starts with the analysis of life issues (dominant concerns) in old age, which was an important task of the project. The results of this "thematic analysis" clearly demonstrate the variety of concerns that people in old age name and describe in a detailed interview. A few statements about the sample as well as the methodology in analyzing the interviews should be made in order to promote a better interpretation of the results of this thematic analysis.

In our sample, we took into account participants from different social classes, people with different degrees of need for care and people in different forms of living (own household, assisted living, living in a nursing home). We did not include people with an (incipient) dementia disease or with depressive and anxiety disorders in the sample. The interview was usually conducted by two people: an interviewer and an interview assistant. At the beginning of the interview, the interviewee was once again informed about the aim of the study: The aim of the study was to get information about how everyday life is personally "structured," about the health and health behavior of older people,

1 In German: "Ich komme, ich weiß nicht von wo, / Ich bin, ich weiß nicht was, / Ich fahre, ich weiß nicht wohin: / Mich wundert, daß ich so fröhlich bin.” Quoted from: Euling 1905, 412.

Ә OpenAccess. () 2021 Andreas Kruse, published by De Gruyter. (cc))BY-NC-ND This work is licensed under the Creative Commons Attribution-NonCommercial-NoDerivatives 4.0 International License. 
about dealing with requirements, challenges and burdens, and finally about what old people do for their physical and mental health and how satisfied they are with their health care.

"Life issues" (in German: "Daseinsthemen") were operationalized in this study in the sense of recurring concerns and topics that were spontaneously expressed and explained in the interviews. The subjects were classified on a 3-point scale with the scale points: 1 = rather low, 2 = medium, 3 = rather high. This scaling was based on three characteristics: (a) the frequency with which events and developments were spontaneously mentioned in relation to the relevant issue in the interview; (b) differentiation of the description of the life issue in the interview (especially enrichment with biographical material); (c) emotional intensity with which the life issue was portrayed (in the sense of an inner participation). (The category system of the life issues was developed in a pilot study with $\mathrm{N}=30$ people.) The mean values $(\mathrm{M})$ and standard deviations (S) for all life issues are given below:

1. Enjoy nature

2. Old age as a special challenge for the psyche

3. Enjoyment of being with other people

4. Physical limitations and losses

5. Experience of being needed by other people

6. Being able to give something to other people

7. Growing importance of the life review

8. Having a task in life

9. Satisfactory / good (physical / mental) health

10. Possibilities for self-responsible living / fulfilling everyday life

11. Stressful pain experience

12. Enjoyment of music / art / literature

13. Faith and transcendence

14. Worry about increasing loneliness

15. Mental gains / spiritual growth

16. Greater reliance on help from other people and institutions

17. Concern for pronounced sensory losses

18. Great interest of other people in old age

19. Concern about cognitive loss and decreasing orientation

20. Phases of painful loneliness

21. Living in your own home

22. Greater reliance on relationships with other people

23. Worrying about giving up one's own apartment or house

24. Experience of devaluation, avoidance by other people
$2.3 \quad .54$

$2.2 \quad .56$

$2.2 \quad .60$

$2.2 \quad .57$

$2.2 \quad .72$

$2.2 \quad .72$

$2.1 \quad .70$

$2.1 \quad .68$

$2.1 \quad .63$

$2.1 \quad .59$

$2.0 \quad .84$

$2.0 \quad .73$

$2.0 \quad .70$

$2.0 \quad .62$

$1.9 \quad .70$

$1.9 \quad .60$

$1.9 \quad .59$

$1.9 \quad .60$

$1.8 \quad .59$

$1.8 \quad .61$

$1.7 \quad .71$

$\begin{array}{ll}1.7 & .69\end{array}$

$1.7 \quad .66$

$1.4 \quad .56$

First of all, these life issues show the great importance of social connectedness for old people; in the third, fifth and sixth life issues ("existential theme") social relations (characterized by reciprocity of given and received support) are reflected. The eighth life issue - having a task in life - speaks of concern for other peo- 
ple; in most interviews, promoting the life situation of other people - particularly of young people - was mentioned as an important task in life. This support could also be of a more "symbolic" nature: the motif of shared responsibility ("world-design" or "shaping the world") was decisive. The life issues also include maintaining independence and health, as well as participation and maintaining personal interests, which shows how differently and comprehensively the task character of life is interpreted subjectively. This topic addresses the integration of self- and world-design. There are five issues (seventh, tenth, thirteenth, fifteenth and sixteenth) in which an increased engagement with one's own self (also in its biographical dimension) is at the centre ("self-design" or "shaping one's person"). Above all, the experience of mental and spiritual maturation in the aging process, the emotional and spiritual gains experienced as well as the growing importance of life stories (biography) argue for this discussion, but experiences of faith and transcendence also point to this. The topic of "joy in nature" has the highest mean; this shows how important access to nature continues to be in old age, how much being involved in nature determines the lifestyle of many people in old age. The topic of "old age as a special challenge for the psyche" has a similar importance to the topic "joy in nature" in the whole group. What is meant by this topic? On the one hand, the experience of increased vulnerability, in topics such as "stressful pain experience," "worrying about pronounced sensory losses," "worrying about cognitive losses and decreasing orientation," "increasing reliance on help from other people and institutions" and "worrying about giving up one's own apartment or house" (due to functional losses, should be added) is clearly expressed. On the other hand are expressed the painful experience of (involuntary) loneliness and the fear of increasing loneliness reflected in corresponding life issues. From the perspective of older people these two experiences are not enough to speak about "special challenges of old age for the psyche."

\section{Self-design and world-design}

The overview of these life issues shows a central motif in old age: namely the integration of self-design and world-design. Of course, this motif can also be seen in earlier phases of life. However, we learned in our study - as well as in a thematically and methodologically related study (Kruse and Schmitt 2015) that this motif does not diminish in old age, rather it retains great importance for the individual. Perhaps it will even go further in old age: cosmic orientation and intergenerational orientation play an important role in the above-mentioned thematic composition. 
The psychological consideration of the potential for self-design and worlddesign in old age leads me to bring together four psychological constructs (detailed in Kruse 2017): (1) introversion with introspection (in the sense of the "deep engagement of people with themselves"), (2) openness (in the sense of "susceptibility to new impressions, experiences and insights that arise from the view of yourself as well as from the view of the surrounding social and spatial world"), (3) concern (in the sense of "willingness to care for other people, to care for the world") and (4) knowledge transfer (in the sense of the "motif to see yourself placed in a sequence of generations and to create continuity and take responsibility through the transfer of knowledge"). These four constructs are briefly explained below. I interpret two of these constructs ("introversion with introspection" and "openness") as characteristics of self-design, and two ("concern" and "knowledge transfer") as characteristics of world-design.

The writing De hominis dignitate (in English: "On the dignity of man”), written by the Florentine scholar Pico della Mirandola in 1427 is classified in the history of philosophy as one of the first fundamental writings on human dignity. Pico introduces this document with the following statements, which focus on the ability of a person to shape him- or herself and shape the world:

At last, the Supreme Maker decreed that this creature, to whom He could give nothing wholly his own, should have a share in the particular endowment of every other creature. Taking man, therefore, this creature of indeterminate image, He set him in the middle of the world and thus spoke to him: "We have given you, Oh Adam; no visage proper to yourself, nor any endowment properly your own, in order that whatever place, whatever form, whatever gifts you may, with premeditation, select, these same you may have and possess through your own judgment and decision. The nature of all other creatures is defined and restricted within laws which We have laid down; you, by contrast, impeded by no such restrictions, may, by your own free will, to whose custody We have assigned you, trace for yourself the lineaments of your own nature. I have placed you at the very centre of the world, so that from that vantage point you may with greater ease glance round about you on all that the world contains. We have made you a creature neither of heaven nor of earth, neither mortal nor immortal, in order that you may, as the free and proud shaper of your own being, fashion yourself in the form you may prefer. It will be in your power to descend to the lower, brutish forms of life; you will be able, through your own decision, to rise again to the superior orders whose life is divine.” $(1990,6$ f.)

In an essay on self-recognition in old age, the philosopher, Arthur Schopenhauer (1788-1860), describes the process as follows:

Towards the end of life, much the same happens as at the end of a masked ball when the masks are removed. We now see who those really were with whom we had come in contact during the course of our life. Characters have revealed themselves, deeds have borne fruit, achievements have been justly appreciated, and all illusions have crumbled away. But, for 
all this, time was necessary. The curious thing, however, is that only towards the end of our lives do we really recognise and understand even ourselves, our real aim and object, especially in our relations to the world and others. Very often, but not always, we shall have to assign to ourselves a lower place than we had previously thought was our due. Sometimes we shall give ourselves a higher, the reason for this being that we had no adequate notion of the baseness of the world, and accordingly set our aim higher than it. Incidentally, we come to know what we have in ourselves. $(2000,491)$

The motif of self-design and world-design mentioned here is also important for a changed understanding of aging. It can often be read that increasing disengagement is associated with increasing age. Gerontological studies, including the one reported here, contradict this assumption. Rather, these studies indicate that the motif of self- and world-design is also "alive" in old age. The contradiction between the assumption on the one hand and empirical findings on the other suggests thinking about a changed understanding of aging.

\author{
A changed understanding of the old person \\ And this thing that we dream of \\ It is nowhere else than in our spirit - \\ We are this once, have travelled ahead of ourselves \\ In the spirit, and beckon us from his hems \\ As who beckons himself \\ (Morgenstern 1986 [1918], 153)
}

This epigram, written by Christian Morgenstern (1871-1914), expresses a challenge that is also significant for the social and cultural understanding of age issues: there is a need for a changed conception of old age. The basis of this new conception is a comprehensive understanding of the person: age must not - as indeed often happens - be reduced to physical processes. It is, rather, expressly necessary to analyze and to understand the cognitive, emotional-motivational and socially communicative qualities of the individual. The cognitive qualities encompass, above all, an overall view, highly developed knowledge systems and effective thinking, learning and memory strategies. The emotional-motivational qualities include, above all, the increasing awareness of one's own self, the embedding of one's own life into wider, cosmic contexts (gerotranscendence) and the growing need to pass on something of one's own life to young people. It also addresses significant preconditions of creativity. Creativity is the ability of people to develop innovative solutions that prove to be particularly successful, addressing both cognitive and everyday practical, emotional and socio-communicative needs. In addition, individual engagement with increased vulnerability may point to creativity - in the sense that innovative coping and processing strat- 
egies form the basis with which experienced boundaries may be transcended and a deeper attitude towards life may be reached.

\author{
Mine are not the years that have taken my time \\ Mine are not the years that may come about \\ The moment is mine, and I'll take care of that \\ So is mine who creates year and eternity. \\ (Andreas Gryphius, quoted in: Maché and Meid 2005, 142)
}

With these reflections on time, Andreas Gryphius (1616-1664) addresses a theme that is also of great significance for a good, personally fulfilled life in old age: it is about being open to recognizing resources and strengths in oneself, to shaping one's life (self-responsibility) and the surrounding world (shared responsibility) and to participating in social as well as cultural development. This is what is meant by the statement 'the moment is mine'. It is not increasing life expectancy that is the ultimate goal, but rather a creative, personally meaningful life, which if this is possible for humans - also places its own resources at the service of other people (co-responsibility) as well as of society (sustainable responsibility) (Frankl 2006 [1959]).

\author{
I lead you behind the world, \\ There you are with you, \\ Unerring, bright - \\ Do the starlings measure death \\ The reed waves the stone, you have \\ Everything \\ For tonight \\ (Celan 1970)
}

This poem, found in the estate of Paul Celan (1920 - 1970), emphasizes the cheerful and unflinching attitude of man with regard to her or his transience and finitude. To be cheerful is not to be equated with good mood; rather, this word refers to the connection between composure, contentment and optimism, even when looking at one's own transience and finitude. Transience and finitude form the central theme of this poem, but at the same time the ability to overcome them internally. Here, the need for comprehensive - and therefore also psychologically, socially and existentially oriented - palliative care become apparent: the alleviation of physical and cognitive symptoms as well as high mental stress with the goal of increasing the individual's ability to consciously experience and shape the dying process.

In discussing developmental potential in old age, it is necessary to combine three perspectives. The first perspective: to what extent was an individual given 
the opportunity and did he or she use this opportunity to realize developmental potentials in the different stages life? The second perspective: to what extent is the individual capable of and motivated towards realizing the developmental potential in old age? Is it appropriate to speak of developmental potential in this phase of life, given the findings of gerontological research? The third perspective: can the potential for development in old age also be interpreted as a sociocultural potential, in this sense that old people contribute to the human capital of society by realizing these potentials? The expression 'Suffering is learning - for ourselves as for others' (Rosen 1987, 68), traced back to Dionysius of Halicarnassus (54 B.C. to 7 A.D.), serves as an illustration of this sociocultural potential of old age.

These three perspectives form the conceptual framework for creativity in old age. The postulate of emotional and motivational as well as mental development throughout the life course suggests the question to what extent older people also have the potential for creativity in thinking and acting and to what extent our society creates opportunities for realizing creativity in old age. Moreover, creativity can be understood to serve as the basis for a role model for succeeding generations.

\section{Creativity}

Creativity is understood as a process in which the individual develops flexible and original approaches to solving novel problems. The development of such approaches is promoted by divergent thinking (Guilford 1967). In contrast to convergent thinking, which by logical inference reaches a single or best solution (the result being more or less completely determined by the information available), divergent thinking provides several alternative solutions, each corresponding to the given requirements. Both the number of solutions generated and their quality are considered a measure of the extent of divergent thinking. In addition to divergent thinking, flexibility in thinking and the ability to create analogies as well as to create unusual associations are mentioned as factors that have a positive effect on creativity; openness to new experiences is cited as a further positive factor (Kruse 2011). The assumption that creativity is the result of a brainstorm is evaluated critically in creativity research. Rather, we need many years of knowledge-building and translation of knowledge into practical work, says Gene Cohen (2005), so that creative potential - which Lev S. Vygotski claims to be in everyone (1976) - becomes creative achievement, becomes long-lasting, sometimes multi-year processes that often precede creative solutions. They form the core of the four-phase model of creativity developed at the beginning of the 
last century by Henri Poincaré: preparation phase, incubation phase, enlightenment, verification (in detail in Wallas 1926). Martin Lindauer (2003) introduces a continuity model of creativity development in his work; he emphasizes that creativity is expressed in different ways in each phase of the curriculum vitae, depending on the specific needs of the individual, as well as on the opportunity structures for the realization of the creative potential.

As susceptibility and curiosity are interpreted as decisive prerequisites on the part of the personality in all phases of life, so this also applies to creativity in later stages of life. It would seem that a child with both high sensitivity and high curiosity could be the parent of such traits to a creative old individual. In order for creativity to be realized, in addition to being receptive to new impressions and curiosity there is also a need for a playful attitude to early stressful life experiences on the part of the individual; here one feels reminded of the concept of "homo ludens" introduced by Friedrich von Schiller in his work on the aesthetic education of man (Schiller 2000 [1795]). George Vaillant (1993, 2002) emphasizes that even old people need to be able to play in order to be creative.

If one considers the question of the essence of creativity from the perspective of the products, then one can name the person's large, long-lasting contributions on the one hand, and the small contributions of the person, their well-being and their surrounding environment, on the other. Decisive for the determination of creativity is the innovation content. To what extent do current emotional, cognitive and socio-communicative performances differ from those that have been achieved so far? Creativity should be defined in terms of the novelty of products, not in terms of their usefulness, their value, their beauty (Carlsson and Smith 2011).

Old age creativity is characterized - if one follows statements on creativity research (Lubart and Sternberg 1998) - by four characteristics: (a) a high degree of subjective experience, (b) a closed form in the sense of unity and harmony, (c) integration of very different ideas and perspectives, (d) a special emphasis on aging processes.

A significant developmental potential in old age consists of the ability to be creative in borderline situations ('Grenzsituationen'). This does not simply mean accepting these situations as something to be tolerated. Rather it means finding a changed attitude towards oneself and the world, modifying partly the criteria of a good life (which conditions have to be given so that I can affirm my life), and finally finding a changed, viable future perspective - which can point beyond earthly existence (cosmic relationships) (Jaspers 2001 [1932]). It seems important to emphasize the creative coping of many old people with borderline situations. Two misunderstandings should be avoided. The first misunderstanding: in old age, life can be continued in exactly the same way as in earlier phases of life 
- diseases, limitations and losses are barely noticeable, physical, cognitive and social activity is limitless. The second misunderstanding: in view of precisely these experienced and objectively verifiable limitations the individual no longer has any developmental potential and does not show any motivation to engage in his own further development. The first misunderstanding: especially in the ninth decade of life physical and cognitive vulnerability increase, susceptibility to disease increases, functional limitations - in sensory and motor skills, but also in individual cognitive features - do clearly exist in the majority of people. And these limitations and losses are also felt very clearly in a subjective way by old people; in their experience, they often constitute a borderline health situation, if only because the individual sees restriction in her or his range of action. Consideration must be given to the vulnerable body because it is often confronted with persistent or phasic pain conditions. From an external point of view, such experiences may not seem like a limit, not something burdensome, not something threatening. In the experience of those people who have to process such restrictions and losses, they do appear as limits, as something burdensome and threatening. Here, not only do medicine, rehabilitation and care need to respond very sensitively but beneficial environments must in part also be created, and beyond that the expression of respect for the dignity of humans in such also subjectively experienced - borderline situations. The second misunderstanding: it is not uncommon to be guided by the assumption that the increased physical and cognitive vulnerability of the individual renders mental and spiritual development potential as well as interest in and engagement for others impossible. Simone de Beauvoir (1972), in her seminal treatise on age - groundbreaking because she practices a found social criticism of social dealings with old people - has already shown that the vulnerability visible to the outside often leads to devaluations, indeed to humiliations of the old people. It is not the age but the vulnerability visible to the outside that she calls the central cause of humiliation. She argues similarly and with increased sharpness, in a book about experiences related to her mother's death.

Especially with regard to old age, it seems necessary to systematically connect two perspectives: those of vulnerability and potential. The vulnerability perspective states that there is a (significantly) increased risk of suffering from a chronic illness or becoming dependent on care, the potential perspective that people over the age of 80 or 85 (that is, in the fourth stage of life) can also have resources and develop them further. Although people are affected by a gradual loss in mobility or by decreasing physical and cognitive performance, they can show strengths and developmental steps in the emotional and motivational area, in the area of personality and in different fields of knowledge, which make it clear how much people can succeed the vulnerability in realizing men- 
tal, emotional, spiritual and social-communicative qualities, or as the philosopher and psychiatrist Karl Jaspers once said: "In life, everything is only so far, is still possibility, still a life in the future, from the new reality, and new action can also interpret the past new and different” $(1973,29)$.

\section{An "example" of creativity in old age: Johann Sebastian Bach}

As an example of creativity in old age, I would like to mention Johann Sebastian Bach's late work, which in music history is referred to as the epitome of musical creativity. The analysis of Johann Sebastian Bach's late work makes it clear that the quantitative perspective ("How extensive is the work?") does not provide a sufficient basis for statements about creativity. What is more important is the qualitative approach, which focuses on features such as depth of workmanship, penetration, complexity, concentration and originality - features that characterize creativity in old age in a special way, and which in many ways can be said to correspond to the creation of a sculpture.

The continuous work on the Art of the Fugue, a process that spans at least eight years, is an expression of this creativity - whereby the ongoing creative process is based on the motif of penetrating even more deeply into the object. This increasing depth of processing does not permit the creation of numerous works. Rather, it requires concentrating on a smaller number of works and giving them full attention. The statement often made in psychological gerontology, according to which aging can be viewed cognitively, emotionally and motivationally as a process of increasing concentration and deepening, is reflected in this peculiarity of the late musical work.

Also worth mentioning is Bach's work on the Missa in B minor and the $M u$ sical Sacrifice. The Missa in B minor was already available in 1735 in an initial but "small” (limited to the Kyrie and Gloria) form. In the last two years of his life Bach realized his wish of creating a Missa tota. To do this, he first used the parody procedure, which means that he used existing compositions which he adapted to the liturgical texts of the mass - albeit often with signs of a profound reworking of the template. The decision to use earlier compositions in numerous parts of the resulting Missa tota was in no way founded on the motif of saving time and completing the mass as quickly as possible. Rather, he was concerned - and a look at the original score of the mass demonstrates this - with thoroughly editing these earlier compositions and raising them to an even higher level of composition in the Missa. In addition to the use of earlier compositions, the 
Missa tota also contains completely new compositions, such as the Credo in unum deum or the Et incarnatus est, compositions that testify to extraordinary musical density and strength as well as the same art of experimentation, and at the same time are able to create a highly moving listening experience: an expression of further increased creativity (detailed in Wolff 2009).

If one condenses and combines the biographical statements that can be made with regard to the last years of Johann Sebastian Bach's life and the musical-symbolic statements on which his last works are based, the following - expressed in first-person form - can be differentiated (the psychological construct to which the respective topic can be assigned is listed in brackets): I live in God, in other people, in my work (relatedness); I perceive my creative powers (creativity); I shape my life (self-design, self-regulation); I dig deeper into music, strive for its completion (creativity); I pass my work on to subsequent generations of musicians (generativity); I take responsibility for other people (shared responsibility); I perceive myself as vulnerable (vulnerability); I perceive myself as part of the divine order (gerotranscendence); I look gratefully at my life, my life as a fragment (ego integrity); I expect the resurrection of the dead, eternal life (religiousness) (detailed in Kruse 2014).

These topics and psychological constructs reflect a rich emotional, mental and spiritual life that makes it clear which creative powers can also be effective in the later stages and at the end of life, provided that this life is related to what motivates them to sense these creative powers and to realize. These "life issues" are clearly recognizable at the end of Johann Sebastian Bach's life: God, family members, students and friends, music. Bach invests a lot of mental and spiritual energy in these relationships.

Helpful here is the concept of "life structures" introduced by Daniel Levinson (1986), in which the personally meaningful relationships to the "others" people, groups, cultures, ideas or places - are reflected, whereby these "others" represent constitutive characteristics of the self in which you invest a high level of psychic energy. The relationship expressed here thus appears as the basis for realizing creative potential as well as for the self-formation of life at the end of life.

\section{Spirituality, transcendence and ego-integrity in the psychology of aging}

In recent decades, there has been a notable increase of interest and respective research on spirituality and religion, in particular on the relationship between 
these concepts and psychological well-being or mental health (Koenig et al. 2012; Kruse and Schmitt 2018). However, there is substantial controversy concerning the appropriate definition of the term spirituality. Overlap between the concepts of religion and spirituality becomes apparent in the respective definitions suggested by Koenig and colleagues. According to these authors, religion involves beliefs, practices and rituals related to the transcendent that may be held or practiced in private or public settings but which are, in some way, derived from established traditions that developed over time within a community. Here, religion is understood as an organized system designed (a) to facilitate closeness to the transcendent, and (b) to foster an understanding of one's relationship and responsibility to others in living together in a community. Likewise, spirituality is distinguished from humanism, values, morals, and mental health by its connection to the transcendent. Spirituality is understood as something intimately connected to the supernatural, the mystical, and (sometimes) to organized religion.

However, some authors further argue that spirituality also extends beyond organized religion and begins before it. To quote one of these authors: "Spirituality includes both a search for the transcendent and the discovery of the transcendent and so involves travelling along the path that leads from non-consideration to questioning, to either staunch non-belief or belief and, if belief, then ultimately to devotion and finally, surrender.” (Koenig et al. 2012, 3) In his philosophy of the present, George Herbert Mead wrote: "We speak of the past as final and irrevocable. There is nothing that is less so [...] the past (or some meaningful structure of the past) is as hypothetical as the future." (1932, 12) Life is organized and structured by people themselves, even in adolescence people begin to create a coherent life story which - in normal circumstances - increasingly becomes a definite story, a basis for reconstructing and understanding the past, for interpreting and evaluating the present, as well as for anticipating the future, setting aims, making plans, goal pursuit and goal adjustment (Birren and Schroots 2006). In psychology, there has long been controversy as to whether self-consistency is an even more important need than self-respect and self-enhancement, since coping with stress and challenges or more general self-regulation processes seem impossible without establishing and maintaining at least some kind of continuity (Seih et al. 2013).

Lars Tornstam (2005), in his theory on gerotranscendence, argues that living into old age, and facing its challenges, brings about a shift in meta-perspective from a materialistic and rational view of the world to a more cosmic and transcendent one. This shift in meta-perspective involves ontological changes on three levels: the cosmic-level, the self-level, and the social-and-individual-relations level. Developing gerotranscendence implies experience of a redefinition 
of self and social relationships, as well as a new understanding of fundamental existential questions. The individual might become less self-occupied, and experience a decreased interest in material things and a greater need for solitary meditation. There is also often a feeling of cosmic communion with the spirit of the universe, and a redefinition of time, space, life and death. There is an increased feeling of affinity with past generations and a decreased interest in superfluous social interaction.

Developing gerotranscendence goes beyond Erik Homburger Erikson's identity status of ego-integrity (Erikson 1998): In Erikson's theory, ego-integration primarily refers to an integration of the elements in the life that has passed. The individual reaches a fundamental acceptance of the life lived. In this way, the ego-integrity described by Erikson is more of a reverse integration process within the same definition of the world as before, while the process of gerotranscendence implies more of a forward or outward direction, including a redefinition of reality (Erikson et al. 1986). In order to characterize gerotranscendence, it is helpful to take up the differentiation between life time (in German: "Lebenszeit") and universal time (in German: "Weltzeit”) introduced by Hans Blumenberg (1986). Differentiating between individual life time and cosmic universal time highlights the human being's motif for transcendence that can be defined as the motif for feeling embedded into a cosmic order in which he or she can trust.

Development of gerotranscendence is seen as a continuous, endogenous process, normally for individuals, instinctive and transcultural, predetermined by genetics: "Ageing, or rather living, implies a process during which the degree of gerotranscendence increases.” (Tornstam 1996, 41) However, not all people in fact develop gerotranscendence when getting old, since the process can be accelerated or retarded by external factors, not least cultural settings: "In most Western cultures neither guidance towards, nor acceptance of, the wise gerotranscendent state of mind exists. In our culture, a person who displays the changes accompanying the gerotranscendence state-of-mind runs the risk of being judged as deviant, asocial or mentally disturbed."

Empirical results point out the increasing willingness of older people to interpret their own lives from a universal perspective where a positively-evaluated religious socialization exists. In this case, the universal perspective not only refers to a cosmic transcendence, but also includes the advance towards generativity, meaning identification with younger people's lives, feeling empathy with them, sharing their concerns, motivating and supporting them. Ahmadi Lewin (2001) analyzed three studies on gerotranscendence in Sweden, Iran, and Turkey. His results further support the hypothesis that "in a cultural setting where mystical-type ideas are not integrated into people's ways of thinking - like the Turkish one - secular people may be expected to have a limited ability to develop 
towards gerotranscendence," whereas societies in which religion is integrated into social and cultural life "provide fertile soil for individuals to develop towards gerotranscendence.” (Ahmadi Lewin 2001, 412)

Let me return to Johann Sebastian Bach's music. From music-historical contributions one can deduce the statement that for Johann Sebastian Bach the death of his first wife represented a border situation that had a traumatic effect on the composer. Bach goes on a six-week concert tour to Carlsbad. He says goodbye to his supposedly completely healthy wife. When he returns after six weeks, he learns that his wife has died and is already buried, and that his four children have been distributed to the family.

How did Bach respond to this loss, to this shock? His compositional work clearly decreases - viewed from a quantitative perspective. However, during the period of mourning, two compositions emerge, which - according to musicological studies - are to be interpreted as a musical tomb for his deceased wife. The first work is the Chaconne from the Partita in D minor for violin solo. There are promising attempts at interpretation, which, however, do not go un-contradicted, according to which Bach had built numerous chorale motifs into the Chaconne; these attempts at interpretation were impressively implemented musically in an exhaustive recording entitled "Morimur." The ability to integrate numerous chorale motifs into a technically and musically highly demanding, far-reaching work is again an expression of the highest creativity. Bach has created a musical tomb here, an epitaph. The Chaconne is one of the most important works of our music history: creativity in a border situation!

The second work is the Chromatic Phantasy and Fugue in D minor for harpsichord solo. This work must contain a particularly intimate message, as Johann Sebastian Bach only agreed to publish it ten years after its creation. This second work - the Phantasy in D minor - now attracts my attention. Let me start with a few explanatory remarks (detailed in Kruse 2014). The piece is divided into three parts. Part (A) is the real 'fantasy part'. Fantasy in music means transcending forms and keys, as is the case in this composition. The very fast tempo and the absence of chords in particular remind us of a fantasy. Maria Barbara, the deceased wife, lives on in the composer's imagination. At the same time in this part an infinite-seeming, intensely felt grief is audible. Part (B) reminds us of the recitatives of the oratorios composed by Bach: one imagines that one hears the evangelists from the passions, who recite and declaim the biblical texts. These are very serious musical texts, which will be heard in part (B). We can say that the death of his wife is lamented and at the same time placed in a Christian-theological order. We might say it is placed at the point of tension between the order of life and the order of death. Part (C) reveals all the 'musical tenderness' of which Bach was capable. It is a physical tenderness (and not 
just a mental one) that the composer places in the musical work, and so it must be played. In addition, Bach goes as far as to modify the harmonies to the utmost and to intertwine them, so that one can say: this already hints at the twelve-tone music of the twentieth century. It is - to put it in metaphors - an impressive spiritual fusion between the composer and his deceased wife. This is where resilience and flourishing come together. What a way to process inner and outer stress, what a form of mental and emotional creativity.

\section{Given vs. lacking openness of society for the potential of old age}

In the late 1980s and early 1990s, the sociologists Matilda W. Riley and John W. Riley published extensive work in which the question was addressed to what extent the individual potentials of old age correspond with structures that promote realizing the individual potentials and thereby contribute to the further development of society and culture (Riley and Riley 1990). This juxtaposition of individual and societal potential should prove to be significant for the further development of gerontological and sociological theory and research. This question is not only of high theoretical-conceptual value - in the sense that it stimulates sociological and gerontological theorizing. It is also of high political and organizational (institutional) importance. Why? The question is whether political actors recognize the mental, emotional and socio-communicative potentials of the old and whether they create the appropriate institutional frameworks to foster the development or realization of these potentials. Organizations and companies are facing a very similar task. What Riley and Riley point out is this: old people with their individual potentials are always ahead; society must follow them in creating appropriate opportunity-structures for fostering the realization of individual potentials. Human beings develop under actually given opportunity structures with the condition that these are determined by the principles of freedom, openness, tolerance and participation - and, I would like to add, new perspectives for the future and new lifestyles, which in turn also constitute a changed, a 'transformed' age. Society needs to respond to this innovation with a continuous change in its structures and institutions - it will necessarily always lag behind the changes on an individual level. Structures and institutions must develop in such a way that they do not block these individual changes and transformations. Old people are basically always new pioneers, new frontiers with respect to changing lifestyles in old age. 
We have recently recognized this very precisely with regard to the active contribution of older people to a civil society. In one part of the already mentioned Generali Old-Age-Study, we interviewed older people (85 years and older), as well as cultural and social institutions, in detail with regard to interest in civic engagement as well as opportunity structures for its implementation (Kruse and Schmitt 2015). It became obvious that almost all cultural and social institutions showed very clearly that, while they are open to civic engagement of people in their third age (60 - 80 or 85 years), they are not open to the involvement of people in their fourth age ( 85 years and older). There were also reasons for the low level of openness to the latter group's commitment: these people - in order to quote a statement which was given very often - would not normally have the physical and mental powers to engage in such a commitment, and they would not be interested in it. They tried to play the role of listeners rather than the role of active agents. However, this statement did not correspond with the selfperception nor with the needs and interests of many people in the fourth age. They emphasized the importance of their care, of their concern for other people - in personal relationships as well as in associations or organizations - including in old age. Even in this phase of their life, they wanted to perceive themselves not only as caregivers, but also as actively (proactively) caring people: here, clubs and organizations can create important public spaces (in the sense of the theory of Hannah Arendt 1958) for action. Not a few emphasized that they felt rejected when their offers to become involved in civil society had been rejected - and they felt humiliated (in the sense of the theory of Avischai Margalit 1996). It's not about blaming associations and organizations here, it's about showing how much the individual and societal potential of old age can diverge: a structural gap that cannot really be reversed, but only reduced; yet its reduction is urgently needed so that the realization of the individual potential of old age can actually succeed.

\section{Conclusions}

When contrasting the emotional, motivational and mental development potential in old age with social attitudes towards old age: what are the consequences? Three important conclusions should be mentioned here. The first: In social (public) discourse, this development potential should be recognized and appreciated much more than in the past and in the present; these potentials should also be considered in their value (or as human capital) for our society. The second: The creativity of older people in coping with existential issues also should be appreciated much more, as this creativity also can serve as an important resource for 
our society. The third: Opportunity structures must be created for an intensive dialogue between old and young people - for a dialogue in which both generations are teachers and learners.

\section{Works cited}

Ahmadi Lewin, Fereshteh. "Gerotranscendence and Different Cultural Settings." Ageing and Society 21.4 (2001): 395- 415.

Arendt, Hannah. The Human Condition. Chicago: Chicago Press, 1958.

Beauvoir, Simone de. Das Alter. Hamburg: Rowohlt, 1972.

Birren, James E., and Johannes J. F. Schroots. "Autobiographical Memory and the Narrative Self Over the Life Span." Handbook of the Psychology of Aging. Eds. James E. Birren and K. Warner Schaie. San Diego, CA: Elsevier, 2006. 477-498.

Blumenberg, Hans. Lebenszeit und Weltzeit. Frankfurt am Main: Suhrkamp, 1986.

Carlsson, Ingegerd M., and Gudmund W. Smith. "Aging." Encyclopedia of Creativity (Vol. I).

Eds. Mark A. Runco and Steven R. Pritzker. London: Elsevier, 2011. 29-32.

Celan, Paul. Nachlass. Marbach: Deutsches Literaturarchiv, 1970.

Cohen, Gene D. The Mature Mind: The Positive Power of the Aging Brain. New York: Basic Books, 2005.

Erikson, Erik H. The Life Cycle Completed (Extended version with new chapters on the ninth stage by Joan M. Erikson). New York: Norton, 1998.

Erikson, Erik H., Joan M. Erikson, and Helen Q. Kivnick. Vital Involvement in Old Age. New York: Norton, 1986.

Euling, Karl. Das Priamel bis Hans Rosenplüt. Studien zur Volkspoesie. Breslau: Verlag M. \& H. Marcus, 1905.

Frankl, Victor E. Man's Search for Meaning. Boston: Beacon Press, 2006 [1959].

Guilford, Joy Paul. The Nature of Human Intelligence. New York: MacGraw Hill, 1967.

Jaspers, Karl. Allgemeine Psychopathologie. 9th ed. Berlin and Heidelberg: Springer, 1973 [1913].

Jaspers, Karl. Philosophie II: Existenzerhellung. 4th ed. Berlin and Heidelberg: Springer 2001 [1932].

Koenig, Harold G., Dana E. King, and Verna B. Carson. Handbook of Religion and Health. New York: Oxford University Press, 2012.

Kruse, Andreas. Ed. Kreativität im Alter. Heidelberg: Universitätsverlag Winter, 2011.

Kruse, Andreas. Die Grenzgänge des Johann Sebastian Bach: Psychologische Einblicke. 2nd ed. Heidelberg: Springer Spektrum, 2014.

Kruse, Andreas. Lebensphase hohes Alter: Verletzlichkeit und Reife. Heidelberg: Springer Spektrum, 2017.

Kruse, Andreas, and Eric Schmitt. "Shared Responsibility and Civic Engagement in Very Old Age." Research in Human Development 12 (2015): 133-148.

Kruse, Andreas, and Eric Schmitt. "Spirituality and Transcendence." Cambridge Handbook of Successful Aging. Eds. Rocío Fernández-Ballesteros, Athanase Benetos, and Jean-Marie Robine. Cambridge: Cambridge University Press, 2018. 426-454. 
Kruse, Andreas, and Eric Schmitt. Eds. “... der Augenblick ist mein, und nehm ich den in Acht." Daseinsthemen und Lebenskontexte alter Menschen. Heidelberg: Heidelberg University Publishing (in press).

Kruse, Andreas, Eric Schmitt, Hartmut Remmers, and Beate Wild. Älterwerden in Balance: Gesundheits- und Bewältigungsverhalten alter Menschen. Cologne: Schriftenreihe der Bundeszentrale für gesundheitliche Aufklärung - Forschung und Praxis der Gesundheitsförderung (in press).

Levinson, Daniel J. “A Conception of Adult Development.” American Psychologist 41 (1986): 3-13.

Lindauer, Martin. Aging, Creativity and Art: A Positive Perspective on Late-Life Development. New York: Kluwer, 2003.

Lubart, Todd I., and Robert J. Sternberg. "Creativity Across Time and Place: Lifespan and Cross-Cultural Perspectives.” High Ability Studies 9 (1998): 59-74.

Maché, Ulrich, and Volker Meid. Eds. Gedichte des Barock. Stuttgart: Reclam, 2005.

Margalit, Avishai. The Decent Society. Cambridge, MA: Harvard University Press, 1996.

Mead, George Herbert. Philosophy of the Present. Chicago: The Open Court Publishing Company, 1932.

Mirandola, Giovanni Pico della. De hominis dignitate. Hamburg: Meiner, 1990.

Morgenstern, Christian. Stufen. Munich: Piper, 1986 [1918].

Riley, Matilda White, and John W. Riley. "Structural Lag: Past and Future." Age and Structural Lag. Eds. Matilda White Riley, and Robert Louis Kahn. New York: Wiley, 1990. 15-36.

Rosén, Haiim B. Ed. Herodoti Historiae (Vol. I: Libri I-IV). Munich: Saur, 1987.

Schiller, Friedrich von. Über die ästhetische Erziehung des Menschen. Stuttgart: Reclam, 2000 [1795].

Schopenhauer, Arthur. Parerga and Paralipomena: Short Philosophical Essays. Oxford: Clarendon Press, 2000.

Seih, Yi-Tai, Michael D. Buhrmester, Yi-Cheng Lin, Chin-Lan Huang, and William B. Swann Jr. "Do People Want to be Flattered or Understood? The Cross-Cultural Universality of Self-Verification." Journal of Experimental Social Psychology 49 (2013): 169-172.

Tornstam, Lars. "Gerotranscendence - A Theory About Maturing in Old Age." Journal of Aging and Identity 1 (1996): 37-50.

Tornstam, Lars. Gerotranscendence: A Developmental Theory of Positive Aging. New York: Springer, 2005.

Vaillant, George E. The Wisdom of the Ego. Cambridge, MA: Harvard University Press, 1993.

Vaillant, George E. Ageing Well: Surprising Guideposts to a Happier Life From the Landmark Harvard Study of Adult Development. Boston: Little, Brown \& Company, 2002.

Vygotski, Lev S. Die Psychologie der Kunst. Dresden: Verlag der Kunst, 1976.

Wallas, Graham. Art of Thought. London: C.A. Watts \& Co., 1926.

Wolff, Christoph. Johann Sebastian Bach. 3rd ed. Frankfurt am Main: Fischer, 2009. 